\title{
Corrosion in Heavy Liquid Metals for Energy Systems
}

\author{
OSMAN ANDEROGLU, ${ }^{1,4}$ ALESSANDRO MARINO, ${ }^{2}$ \\ and PETER HOSEMANN ${ }^{3}$ \\ 1.-University of New Mexico, Albuquerque, NM, USA. 2.-SCK-CEN, Mol, Belgium. \\ 3.-University of California, Berkeley, CA, USA. 4.—e-mail: oanderoglu@unm.edu
}

Heavy liquid metals (HLMs) such as molten $\mathrm{Pb}$ and lead bismuth eutectic (LBE) are being proposed as heat transport fluids in advanced nuclear and concentrated solar power systems because of their low vapor pressure, excellent thermophysical (high boiling point and thermal conductivity) and neutronic properties, and thermal energy storage potential. However, HLM compatibility with structural materials including corrosion and liquid metal embrittlement is among the main challenges preventing widespread applications in energy systems. To control the structural material interaction with the HLM, one has to pay close attention to the HLM chemistry. The HLM chemistry in combination with the material-to-HLM interaction is key to enabling this technology. This special topic provides a platform to highlight recent advances addressing challenges involving heavy liquid metal coolantmaterial interactions.

The paper by C. Schroer entitled "Dissimilar metal solution from solid alloys as observed for steels and nickel-based alloys in the presence of lead-based liquid alloys or liquid tin" gives a detailed overview of metal dissolution mechanisms in liquid LBE and Sn. The work identified shows microstructural analysis of the alloy after exposure in liquid $\mathrm{LBE}$ or $\mathrm{Sn}$ and found that the oxygen concentration in liquid metal supports leaching especially of oxide-forming elements.

P. Hosemann et al. studied the compatibility of additively manufactured $\mathrm{FeCrAl}$ in stagnant $\mathrm{LBE}$ at $600^{\circ} \mathrm{C}$ in the work "Corrosion testing of additively manufactured Fe-Cr-Al alloy in LBE". It was found

O. Anderoglu, A. Marino, and P. Hosemann are Guest Editors for the Corrosion and Environmental Effects Committee and Nuclear Materials Committee of TMS. They coordinated the topic Corrosion in Heavy Liquid Metals for Energy Systems in this issue.

(Received October 1, 2021; accepted October 3, 2021;

published online October 22, 2021) that additively manufactured $\mathrm{FeCrAl}$ can experience significant corrosion phenomena if not preconditioned. A short oxidation treatment prior to $\mathrm{LBE}$ exposure of the $\mathrm{FeCrAl}$ material mitigates this issue under the test condition evaluated here.

The work by B. Pint et al. studied the performance of alumina-forming austenitic (AFA) steels with different $\mathrm{Ni}$ and $\mathrm{Mn}$ contents in static and flowing high-purity molten lead at $500-800^{\circ} \mathrm{C}$. Velocity of the $\mathrm{Pb}$ in the thermal convection loop was determined to be $0.8 \mathrm{~cm} / \mathrm{s}$ at $650^{\circ} \mathrm{C}$. After exposure for $1000 \mathrm{~h}$, the mass losses for AFA alloys were generally low suggesting good compatibility under test conditions without pre-oxidation in "Compatibility of Alumina-Forming Austenitic Steels in Static and Flowing Pb".

J. Lim et al. measured oxygen oversaturation in $\mathrm{Pb}$ using thermal cycle method for the first time in "Solubility of oxygen and metastable limit for $\mathrm{PbO}$ nucleation in liquid $\mathrm{Pb}$ ". First, they measured oxygen partial pressure and Sieverts' constant of the dissolved oxygen in $\mathrm{Pb}$ using electrochemical methods. Then, the oxygen solubility was calculated and a temperature correlation was derived at 623 $790 \mathrm{~K}$.

The research performed by J. Choi et al. designed a rotating disc experiment to study flow accelerated corrosion of $316 \mathrm{~L}$ in $\mathrm{LBE}$ at $600^{\circ} \mathrm{C}$ and up to $3.14 \mathrm{~m} /$ $\mathrm{s}$ linear velocity for $150 \mathrm{~h}$. They found that above $2 \mathrm{~m} / \mathrm{s}$ LBE affected zone is less sensitive to flow velocity and that erosion starts at $\sim 3 \mathrm{~m} / \mathrm{s}$ in "Flow Accelerated Corrosion of Stainless Steel 316L by a Rotating Disk in Lead Bismuth Eutectic Melt".

F. Schmidt et al. showed feasibility of using proton-induced x-ray emissions (PIXE) to investigate corrosion behavior of pure $\mathrm{Fe}$ in $\mathrm{LBE}$ at $450^{\circ} \mathrm{C}$ while under $4 \mathrm{MeV}$ proton irradiation by studying the thickness change in "Continuous Monitoring of Pure Fe Corrosion in Lead-Bismuth Eutectic Under Irradiation with Proton-Induced X-ray Emission Spectroscopy". 
K. Talaat et al. proposed that neutronics can be used as a passive means to monitor corrosion. The work "Leveraging neutronics to monitor mass transfer corrosion in lead and lead-bismuth cooled reactors" shows that transfer of nickel from the cladding to the coolant contributed significant positive reactivity to the system through reduced parasitic neutron absorption in the active core.

In "Influence of phase-structural state on corrosion behavior of chromium steels in static liquid lead under loads", V. Fedirko et al. studied corrosion of ferritic $(\mathrm{Fe}-11 \mathrm{Cr})$ and austenitic $(\mathrm{Fe}-18 \mathrm{Cr})$ steels at $550^{\circ} \mathrm{C}$ in oxygen-controlled stagnant lead up to $1000 \mathrm{~h}$ and reported corrosion along the grain boundaries (GBs). This leads to etching of GBs and penetration of lead while causing dissolution of the alloying elements including $\mathrm{Ni}, \mathrm{Cr}$ and, $\mathrm{Mn}$. It was also established that the applied loads accelerate the corrosion.

All titles and authors of the articles published under the topic "Corrosion in Heavy Liquid Metals for Energy Systems" in the December 2021 issue (vol. 73, no. 12) of JOM can be accessed via the journal's page at: http://link.springer.com/journal/1 1837/73/12/page/1.

Publisher's Note Springer Nature remains neutral with regard to jurisdictional claims in published maps and institutional affiliations. 